\title{
Flow and Mass Transfer Performance in Short Pin-Fin Channels with Different Fin Shapes
}

\author{
R.J. GOLDSTEIN * and S.B. CHEN \\ Heat Transfer Laboratory, Department of Mechanical Engineering, University of Minnesota, Minneapolis, \\ $M N 55455$, USA
}

(Received in final form 2 May 1996)

\begin{abstract}
The mass transfer (analogous to heat transfer) and pressure loss characteristics of staggered short pin-fin arrays are investigated experimentally in the range of Reynolds number 3000 to 18,000 based on fin diameter and mean approach-flow velocity. Three different shapes of fins with aspect ratio of 2 are examined: one uniform-diameter circular fin (UDCF) and two stepped-diameter circular fins (SDCF1 and SDCF2). Flow visualization using oil-lampblack reveals complex flow characteristics associated with the repeated production of horseshoe vortices and fin wakes, and the interactions among these. The SDCF1 and SDCF2 arrays show flow characteristics different from the UDCF array due to downflow from the steps. For all arrays tested, the near-endwall flow varies row by row in the initial rows until it reaches a stable pattern after the third row. The row-averaged Sherwood numbers obtained from the naphthalene sublimation experiment also show a row-by-row variation pattern similar to the flow results. While the SDCF2 array has the highest mass transfer rate, the SDCF1 array has the smallest pressure loss at the same approach-flow velocity. The fin surfaces have higher array-averaged Sherwood number than the endwall and the ratio between these changes with fin shape and Reynolds number. The performance of the pin-fin arrays is analyzed under two different constraints: the mass/heat transfer rate at fixed pumping power, and the mass/heat transfer area and pressure loss to fulfill fixed heat load at a fixed mass flow rate. In both cases, the SDCF2 array shows the best performance.
\end{abstract}

Keywords: Short pin-fin array, Mass/heat transfer, Visualization, Performance

\section{INTRODUCTION}

Pin-fin arrays have been widely used as an effective tool to enhance convective heat transfer in many engineering applications. Studies for the short pinfin array whose length spans the entire flow passage have been conducted from the late 1970s with particular emphasis on internal cooling at the trailing edge part of advanced gas turbine blades. Numerous studies were conducted to examine parameters such as the fin length-to-diameter ratio (Brigham and VanFossen, 1984), array geometry (Metzger et al., 1981; 1983; Metzger and Haley, 1982), and entrance length (Lau et al., 1985). To

\footnotetext{
*Corresponding author. Tel.: (612) 625-5552. Fax: (612) 625-3434. E-mail: rjgumn@mailbox.mail.umn.edu.
} 
improve heat transfer performance, the effect of fin shape on heat transfer and pressure loss was investigated using an oblong shaped fin (Metzger et al., 1984) and a partial length fin (Peng, 1984). The heat transfer and pressure loss in the presence of lateral flow ejection (Lau et al., 1989a,b), channel convergence, array interruption, and the change of array configuration (Steuber and Metzger, 1986), and fin-endwall fillet (Chyu, 1989) were also investigated to simulate specific operating conditions for the internal cooling of a turbine blade.

These studies reveal that short pin-fin arrays produce significant enhancement of heat transfer on the channel wall. However, this increased heat transfer is accompanied by a large increase in pressure drop (Metzger et al., 1983; Lau et al., 1989a,b). In most applications of pin fins, both the heat transfer and the pressure loss characteristics are important. To improve the heat transfer and pressure loss characteristics of the short pin-fin array, better understanding of the physical mechanisms which govern both the heat transfer and the pressure loss is essential. Due to the small lengthto-diameter ratio, much of the heat transfer area of the short pin-fin channel is affected by the strong endwall-cylinder interactions. Several reports show high mass transfer near the base of a protruding cylinder in a developing boundary layer (Goldstein and Karni, 1984; Van Dresar and Mayle, 1986). The horseshoe vortices generated at the cylinderendwall junction played an important role in heat transfer enhancement on both the cylinder and the endwall. Ireland and Jones (1986) observed horseshoe vortices near the fin-endwall junction in a fully developed duct flow, which led to an augmentation of heat transfer from the duct wall in the vicinity of the cylinder. Mass transfer and flow characteristics on the endwall of a short protruding cylinder with a free end were reported in Goldstein et al. (1985) and Kawamura et al. $(1984,1985)$. They observed that the fluid flowing over the free end of a short protruding cylinder is dragged into the wake toward the endwall increasing the heat transfer on the endwall.

Based on these results, a new fin shape which has potential to improve the heat/mass transfer and pressure loss characteristics was designed: steppeddiameter fins with stepwise change of diameter in the fin axial direction such that the cylinders at both ends have equal diameters and the one in the middle has a reduced diameter. The mass transfer and pressure loss characteristics of the stepped-diameter circular fin arrays were studied by Goldstein $e t$ al. (1994) and Chen et al. (1994). They found that the stepped-diameter circular fin array produces higher mass transfer and less pressure loss than the uniform-diameter circular fin array. However, only the mass transfer from the fins was measured in those studies. The present study is an extension of that work. Flow visualization using oil-lampblack is performed to improve understanding of the flow characteristics. Measurement of local mass transfer coefficients on the endwall is conducted using naphthalene sublimation. The mass transfer, pressure loss, and overall performance of the pin-fin arrays are analyzed using the measured data.

\section{EXPERIMENTAL APPARATUS AND PROCEDURES}

The experiments are performed in a specially designed open-circuit suction-type wind tunnel, the schematic of which is presented in Fig. 1. The tunnel is composed of an inlet baffle plate, rectangular duct, plenum chamber, orifice metering section, flow control valve, blower, and exhaust duct. Naphthalene-vapor-free air is drawn into the horizontal rectangular duct through a sharp-edged, circular baffle plate and vented out of the laboratory through the exhaust duct. The inner crosssection of the rectangular duct is $133.4 \mathrm{~mm}$ width by $26.7 \mathrm{~mm}$ height and the total length is $2728 \mathrm{~mm}$. The resulting duct aspect ratio $(W / H)$ is 5 to 1 and the hydraulic diameter $\left(D_{\mathrm{h}}\right)$ is $44.5 \mathrm{~mm}$. The rectangular duct is composed of three sections. The entrance section with length of $1838 \mathrm{~mm}\left(41.3 D_{\mathrm{h}}\right)$ serves as the hydrodynamically developing region. The exit section with length of $547 \mathrm{~mm}\left(12.3 D_{\mathrm{h}}\right)$ serves as the hydrodynamically redeveloping region. The test section with length of $333 \mathrm{~mm}\left(7.5 D_{\mathrm{h}}\right)$ is 


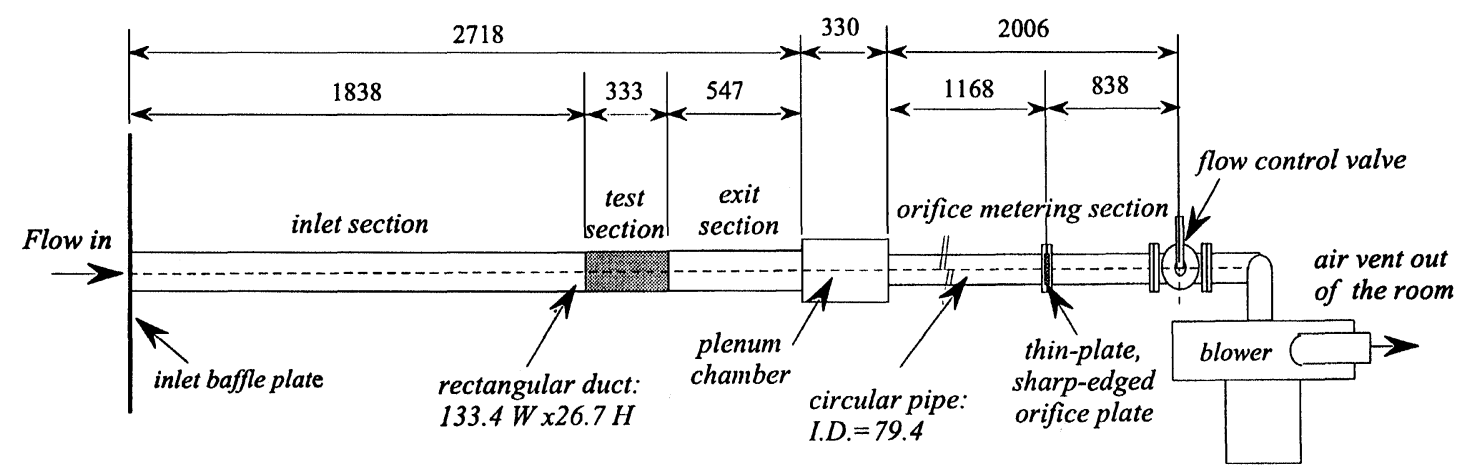

FIGURE 1 Schematic view of the wind tunnel for the pin-fin array experiment (dimensions in $\mathrm{mm}$ ).

located between these two and contains the pin-fin array. Twenty-seven pressure taps are located on the top wall along the streamwise direction to measure the pressure drop. A thin plate, sharp-edged orifice meter is used to measure air flow rate.

The three fin shapes used in this study are presented in Fig. 2. One is a uniform-diameter circular fin (denoted by UDCF). The other two are steppeddiameter circular fins (denoted by SDCF). All fins have the same diameter at both ends $(d=13.34 \mathrm{~mm})$ and total length $(H=26.67 \mathrm{~mm})$, with the resulting length-to-diameter ratio $(H / d)$ of 2 . Both stepped fins have the same reduced diameter in the middle $\left(d_{\mathrm{m}}=9.33 \mathrm{~mm}\right)$ and, accordingly, a diameter reduction ratio $\left(d_{\mathrm{m}} / d\right)$ of 0.7 . The difference between the two stepped fins is in the location of the steps in the direction of the fin axis: SDCF1 has a step lengthto-total-length ratio $\left(H_{\mathrm{s}} / H\right)$ of $1 / 4$, and the SDCF2 has $H_{\mathrm{s}} / H$ of $1 / 3$.

The experiments are performed in the range of Reynolds number 3000 to 18,000 , based on mean approach flow velocity and fin diameter. The Reynolds number, based on mean approach flow velocity and hydraulic diameter, varies from 10,000 to 60,000 . Mass transfer coefficients on the fins and endwall are measured separately. When the mass transfer on the fins is measured, only the fin surface is naphthalene active and the endwalls are naphthalene inactive. When the endwall mass transfer is measured, only the top and bottom endwalls are naphthalene active and fins are naphthalene inactive. Row-average mass transfer coefficients were

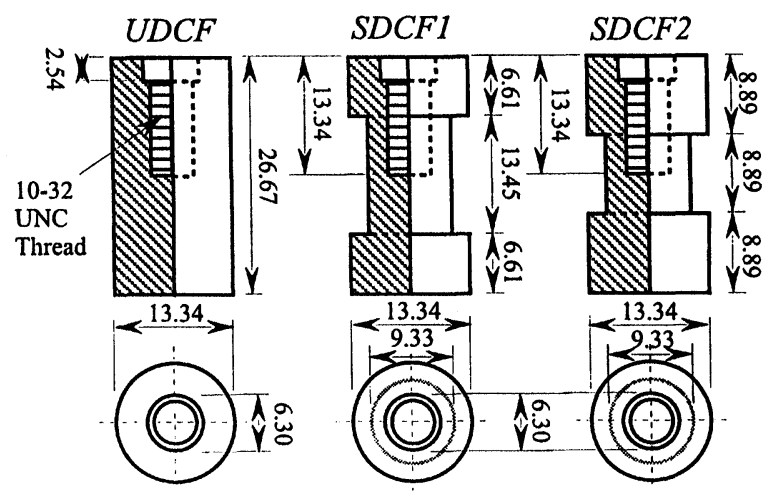

FIGURE 2 Shapes of fins for the pin-fin array experiment (dimensions in $\mathrm{mm}$ ).

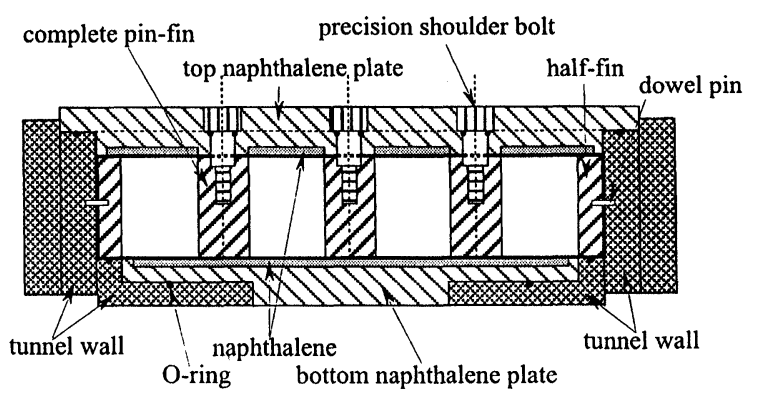

FIGURE 3 Cross-sectional view of the pin-fin channel.

measured on the fins in previous study. Since the details of this measurement are presented in Goldstein et al. (1994), only the method used for the endwall measurement is described here. Figure 3 shows cross-sectional view of the pin-fin channel. 
The top and bottom wall of the test section is interrupted to fit with the naphthalene plate during the mass transfer experiment. The top naphthalene plate also serves to hold pin-fins in the desired array geometry. The plate surface is machine cut by $2.54 \mathrm{~mm}$ depth except at the 35 circular fin sites and side rims to fill in with the naphthalene. Precise positioning and attachment of the pin-fins in the array configuration are accomplished using the precision shoulder bolts with dowel-fin quality shoulders and 35 holes of $6.35 \mathrm{~mm}$ diameter (same diameter as the shoulder bolts) on the top naphthalene plate drilled precisely according to the array configuration. Each hole has a circular rim whose outside diameter is the same as the fin diameter and elevation is the same as the side rims to prevent elevation change of the naphthalene surface due to the force exerted by the shoulder bolt during the assembling process. The $2.54 \mathrm{~mm}$ wide side rims are used as a reference plane for the elevation change measurement. Ten half-fins are attached to the side walls using the dowel fins. Three T-type (copperconstantan) thermocouples are embedded in the naphthalene layer to monitor the temperature during the experiment. The bottom naphthalene plate provides a symmetric mass transfer boundary condition, but most of the measurements are carried out using the top naphthalene plate. When assembled, the fins attached on the top plate softly touch the bottom naphthalene surface.

Figure 4 shows the array configuration. The fins are arranged in a staggered manner with the same streamwise and cross-stream pitch-to-diameter ratios $S_{x} / d=S_{z} / d=2.5$. The number of rows in streamwise direction is 10 . The odd number rows have 3 complete fins and 2 half fins; the even number rows have 4 complete fins. The half fins are used to simulate a large number of cross-stream fins. The naphthalene active boundary condition begins 1.25 diameters upstream from the axis of the first-row fins and ends 1.25 diameters downstream from the last-row fin axis. The naphthalene coating is in the rectangular domain, $0 \leq x / d \leq 25$ and $-4.81 \leq z / d \leq 4.81$, as marked using dotted lines in the figure. The shaded area in the figure is the measurement domain of the local mass transfer coefficients. This domain can be described as $-2.5 \leq z / d \leq 2.5$ and $0 \leq x / d \leq 25$.

To calculate the local mass transfer coefficient, the local elevation changes on the naphthalene

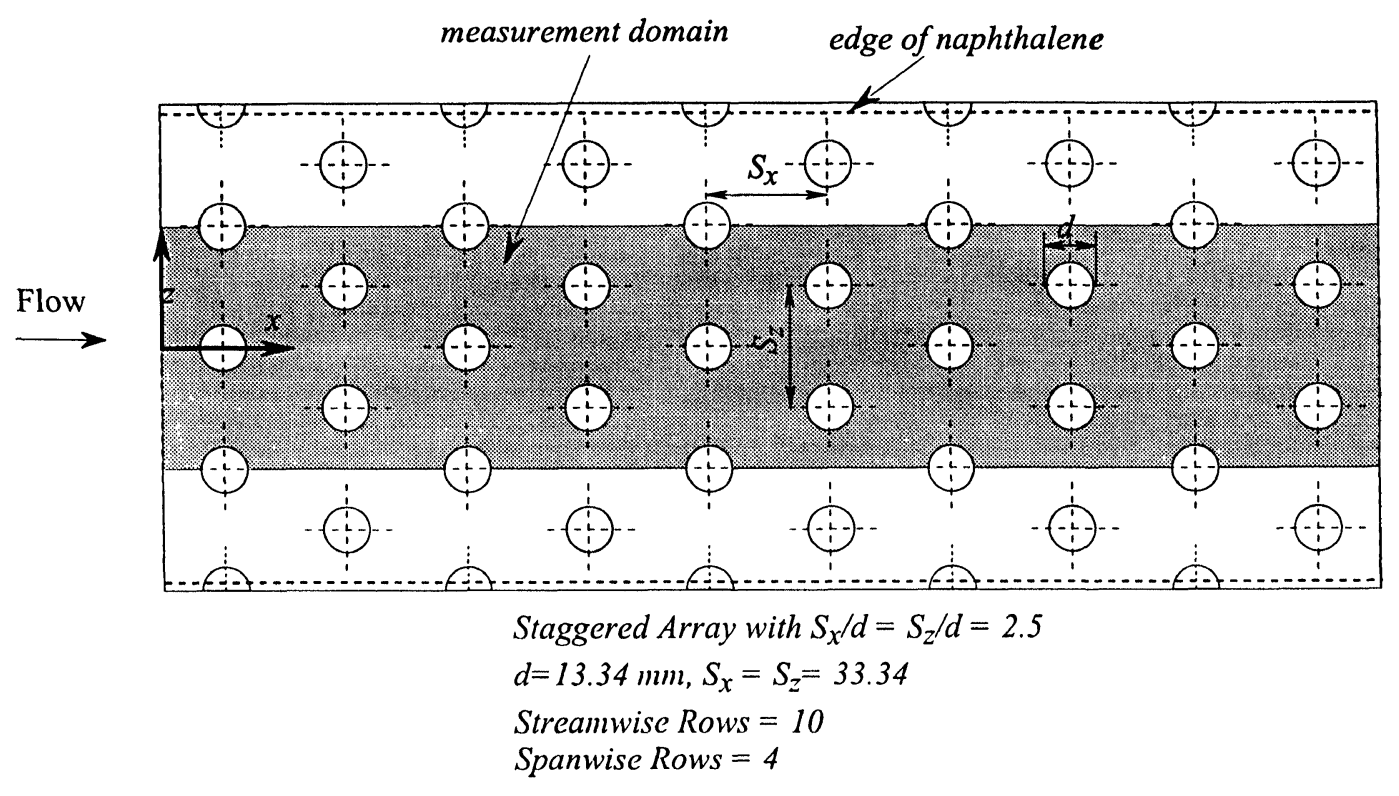

FIGURE 4 Array configuration of the pin-fin array. 
surface due to sublimation during the test period are determined. The local elevations of the naphthalene surface are measured before and after the test run. The difference in local elevations between these two measurements is the change in naphthalene thickness induced by the sublimation. Since the determined local elevation changes include extraneous sublimation during the measurement period and the transient period between the measurement and wind tunnel run, those are compensated using an experimentally determined natural convection sublimation rate. Measurement is performed using a computer-controlled, automated surface profile measurement system the details of which are described in Goldstein et al. (1985). Non-uniform rectangular measurement grids are used for the measurement: the measurement points are spaced more closely in the regions with high mass transfer gradient than in the regions with low mass transfer gradient. There are 29 and 150 points along the $z$ and $x$-axis, respectively for a total of 4350 measurement points. The measurement time between two consecutive data points depends on the time duration for the positioning of depth gauge, stabilizing of the depth gauge after movement, and transmission and storage of data. Typical time required to measure one set of data (4350 points) was about $120 \mathrm{~min}$.

\section{DATA REDUCTION}

Mass transfer using naphthalene $\left(\mathrm{C}_{10} \mathrm{H}_{8}\right)$ sublimation is used in this study. As discussed in many previous works, the measured mass transfer coefficient can be converted to a heat transfer coefficient using the analogy between heat and mass transfer (Eckert, 1976). The technique enables accurate measurement of transport coefficients in the region with high transport coefficient gradient without conduction error. The naphthalene-active and naphthalene-inactive wall boundary conditions in the present experiment are equivalent to isothermal wall and adiabatic wall boundary conditions, respectively, in a heat transfer experiment. The local mass transfer coefficient is determined from,

$$
h_{m}(x, z)=\frac{\ddot{m}(x, z)}{\left(\rho_{\mathrm{n}, \mathrm{w}}-\rho_{\mathrm{n}, \mathrm{b} x}\right)},
$$

where $\ddot{m}(x, z)$ is the local mass transfer rate per unit area and $\left(\rho_{\mathrm{n}, \mathrm{w}}-\rho_{\mathrm{n}, \mathrm{b} x}\right)$ is the difference between naphthalene vapor concentration at the naphthalene surface and the bulk concentration of naphthalene vapor in approaching air at the streamwise station $x$. The local mass flux $\ddot{m}(x, z)$ can be determined by

$$
\ddot{m}(x, z)=\frac{\rho_{\mathrm{s}} \delta y}{\delta \tau},
$$

where $\rho_{\mathrm{s}}$ is a density of solid naphthalene, $\delta y$ is a local net sublimation loss (change in thickness of naphthalene), and $\delta \tau$ is the exposure time in the flow. Substituting Eq. (2) into Eq. (1) yields

$$
h_{m}=\frac{\rho_{\mathrm{s}}}{\left(\rho_{\mathrm{n}, \mathrm{w}}-\rho_{\mathrm{n}, \mathrm{b} x}\right)} \frac{\delta y}{\delta \tau} .
$$

The naphthalene vapor concentration at the wall, $\rho_{\mathrm{n}, \mathrm{w}}$, is calculated from the vapor pressuretemperature relation of naphthalene by Ambrose et al. (1975) in conjunction with the ideal gas law. The bulk concentration of naphthalene vapor in the approaching air at the axial station $x, \rho_{\mathrm{n}, \mathrm{b} x}$, can be calculated from a mass balance in the following way. The surface integrated mass transfer rate between $x=0$ to $x$ and $-S_{z} \leq z \leq S_{z}$ is determined by numerically integrating $\ddot{m}(x, z)$ using

$$
\dot{M}_{0-x}=2 \int_{0}^{x} \int_{-S_{z}}^{S_{z}} \ddot{m}(x, z) \mathrm{d} z \mathrm{~d} x
$$

where the factor 2 accounts for the mass transfer from both top and bottom surfaces and $\ddot{m}(x, z)$ values at the fin sites are set to zero. From the mass balance, $\rho_{\mathrm{n}, \mathrm{b} x}$ becomes

$$
\rho_{\mathrm{n}, \mathrm{b} x}=\rho_{\mathrm{n}, \mathrm{b} 0}+\dot{M}_{0-x} / \dot{V},
$$

where $\rho_{\mathrm{n}, \mathrm{b} 0}$ is the naphthalene vapor concentration in the flow approaching the test section and $\dot{V}$ is the volume flow rate of air passing through the 
channel between $-S_{z} \leq z \leq S_{z}$. Since the inlet air flow is naphthalene free, $\rho_{\mathrm{n}, \mathrm{b} 0}$ is zero in this study. The resulting local mass transfer coefficients are presented in terms of the local Sherwood number which is defined by

$$
S h_{d}=\frac{h_{m} d}{D_{\mathrm{na}}},
$$

where $d$ is the diameter of the fins and $D_{\text {na }}$ is the binary diffusion coefficient of naphthalene in air. Values of $D_{\text {na }}$ measured by many investigators show large discrepancies. Based on Goldstein and Cho (1995), $D_{\text {na }}$ is calculated from

$$
D_{\mathrm{na}}=0.0681\left(\frac{T_{\mathrm{w}}}{298.16}\right)^{1.93}\left(\frac{1.013 \times 10^{5}}{P}\right),
$$

where $D_{\text {na }}$ is in $\mathrm{cm}^{2} / \mathrm{s}, T_{\mathrm{w}}$ is the naphthalene temperature at the wall in kelvin, and $P$ is the pressure in pascal. The averaged Sherwood numbers are calculated from the local Sherwood number. The row-averaged Sherwood number at the $i$ th row is calculated from

$$
\begin{aligned}
\overline{S h_{d, \mathrm{r} i}}=\frac{1}{A_{\mathrm{w}}} & A_{\mathrm{w}, \mathrm{fin}}\left(\overline{S h_{d, \mathrm{ri} i}}\right)_{\mathrm{fin}} \\
& \left.+A_{\mathrm{w}, \text { endwall }}\left(\overline{S h_{d, \mathrm{ri} i}}\right)_{\text {endwall }}\right],
\end{aligned}
$$

where $A_{\mathrm{w}, \text { fin }}, A_{\mathrm{w}, \text { endwall }}$, and $A_{\mathrm{w}}$ are mass transfer area on the fin, endwall, and fin-endwall combined surface in the $i$ th row of the array, respectively. The row-averaged Sherwood number on the fin is taken from Goldstein et al. (1994) and on the endwall is calculated from present results using

$$
\begin{aligned}
& \left(\overline{S h_{d, \mathrm{ri} i}}\right)_{\text {endwall }} \\
& \quad=\frac{1}{2\left(S_{x} S_{z}-A_{\mathrm{f}, \mathrm{b}}\right)} \int_{X_{\mathrm{s}, i}}^{X_{\mathrm{e}, i}} \int_{-S_{z}}^{S_{z}} S h_{d}(x, z) \mathrm{d} z \mathrm{~d} x,
\end{aligned}
$$

where $S_{x}$ and $S_{z}$ are streamwise and cross-stream pitches of the array, respectively. $A_{\mathrm{f}, \mathrm{b}}$ is the fin base area, and $X_{\mathrm{s}, i}$ and $X_{\mathrm{e}, i}$ represent the streamwise location $S_{x} / 2$ upstream and downstream from the $i$ th row fin axis, respectively. The fully developed Sherwood number and the array-averaged Sherwood number are also used. When the
Sherwood number remains approximately constant for rows downstream of the $n$th row, the fully developed Sherwood number is calculated from

$$
\overline{S h_{d, \mathrm{f}}}=\frac{1}{10-n} \sum_{i=m+1}^{10} \overline{S h_{d, \mathrm{r} i}} .
$$

The array-averaged Sherwood number is calculated from

$$
\overline{S h_{d, \mathrm{a}}}=\frac{1}{10} \sum_{i=1}^{10} \overline{S h_{d, \mathrm{ri}}} .
$$

Two types of Reynolds numbers are used to characterize the flow condition

$$
R e_{d, \mathrm{~m}}=\frac{\rho u_{\max } d}{\mu} \text { and } R e_{d, \mathrm{a}}=\frac{\rho u_{\mathrm{ave}} d}{\mu},
$$

where $u_{\max }$ is the maximum velocity inside the pinfin channel and $u_{\text {ave }}$ is the mean approaching flow velocity. Note that these two Reynolds numbers are related by

$$
R e_{d, \mathrm{a}}=R e_{d, \mathrm{~m}}\left(\frac{A_{\mathrm{min}}}{A_{\mathrm{duct}}}\right),
$$

where $A_{\text {duct }}$ is a cross-sectional area of rectangular duct and $A_{\min }$ is a minimum free flow area. The value of $A_{\min }$ depends on the fin shape. The $A_{\min } /$ $A_{\text {duct }}$ values of the UDCF, SDCF1 and SDCF2 arrays are $0.60,0.66$ and 0.64 , respectively.

The uncertainty in Sherwood number is evaluated based on $95 \%$ confidence level described in Kline and Mcklintock (1953). The estimated uncertainty in Sherwood number in this experiment is about $7 \%$. The largest contributor to this uncertainty is the binary diffusion coefficient of naphthalene in air which has $5.1 \%$ of uncertainty. More details of the uncertainty analysis are given in Chen (1996).

\section{RESULT AND DISCUSSION}

\section{Flow Visualization}

The photographs presented in Fig. 5 represent the endwall flow of the UDCF, SDCF1, and SDCF2 
(a) UDCF array

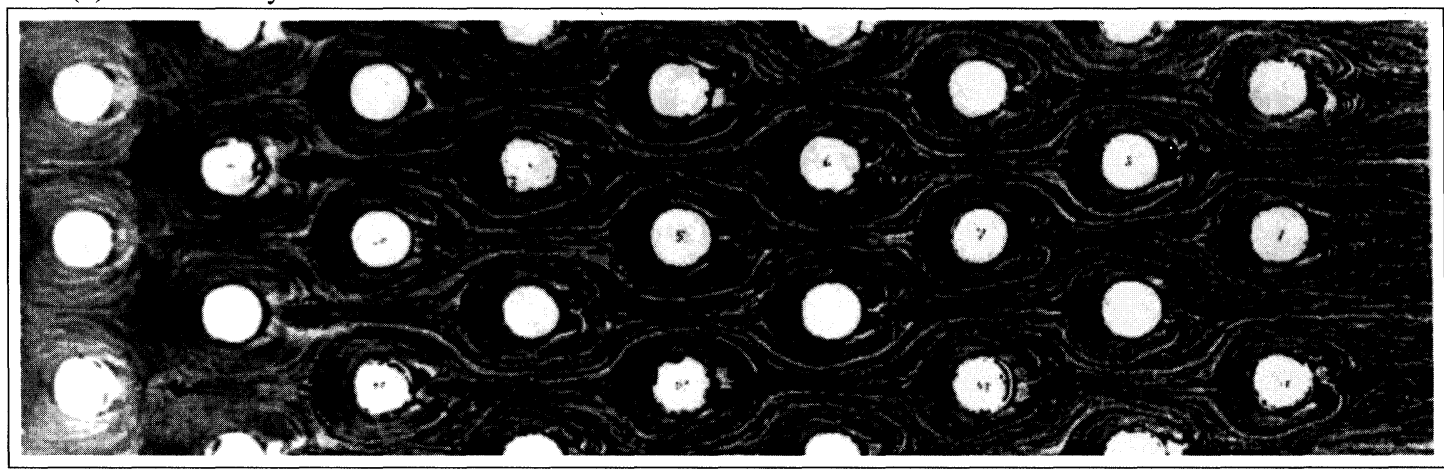

(b) SDCF1 array

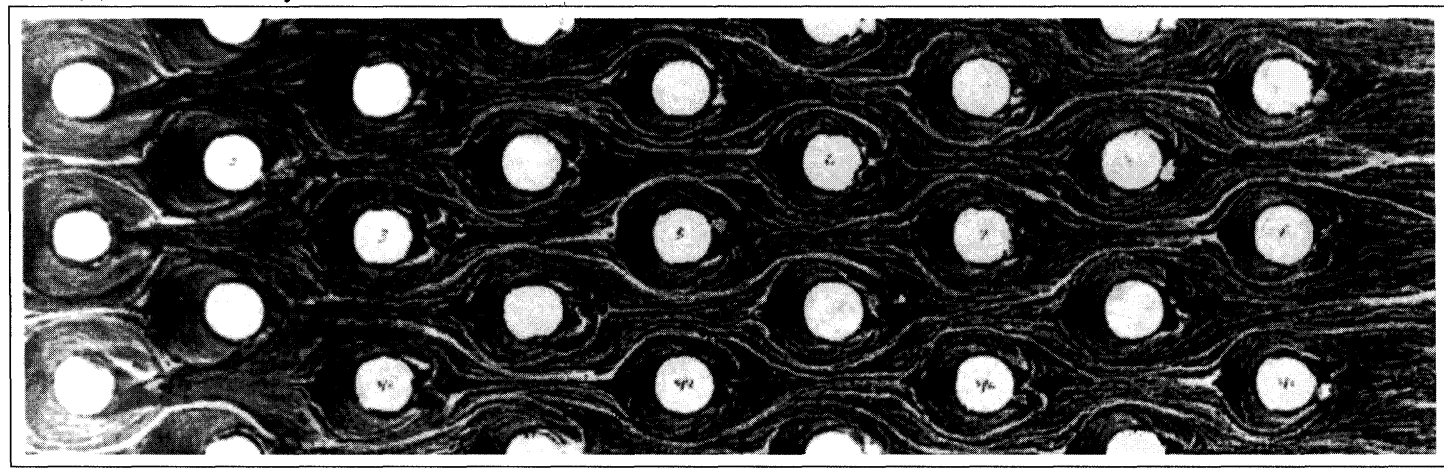

(c) SDCF2 array

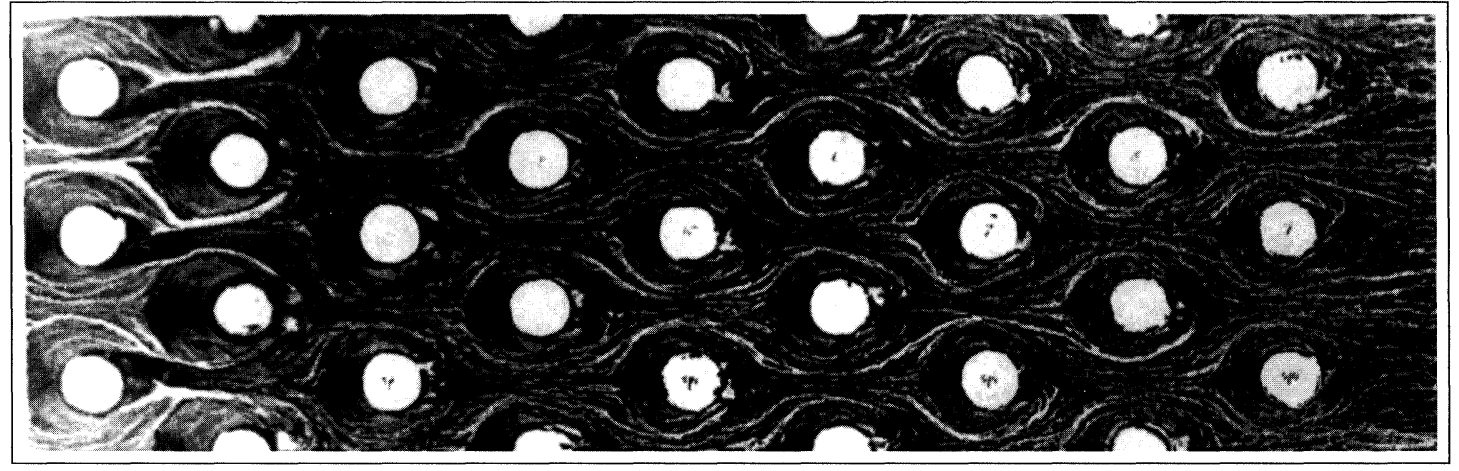

FIGURE 5 Near endwall flow of the UDCF, SDCF1, and SDCF2 arrays.

arrays visualized using an oil-lampblack mixture at $R e_{d, \mathrm{a}}=18,000$. As observed from these photographs, the near-endwall flow in the pin-fin arrays is extremely complex due to the repeated production of the horseshoe vortices and fin wakes, and their interactions imposed by the repeated blockage of the fins. It is well known that when the boundary layer developing over a flat surface encounters a surface mounted obstacle, the mean shear within the approaching boundary layer is 
skewed due to the adverse pressure gradient present at the leading edge of the obstacle, Baker (1980) and Goldstein and Karni (1984). The boundary layer separates and rolls up to form a series of vortices at the leading edge, and vortices wrap around the obstacles with the main flow leaving streamwise vortex legs at both sides of the obstacle. These vortices are termed horseshoe vortices or necklace vortices because of their shape.

For the UDCF array in Fig. 5(a), there exist traces of horseshoe vortices and a saddle point at the upstream of each fin in all rows. Another saddle point caused by the recirculation of flow exists downstream of the fins. A noteworthy thing is the change of surface flow with streamwise row number. The regions affected by the horseshoe vortices and recirculation (or the distance from the leading edge of a fin to the front saddle point and from the rear edge of a fin to the rear saddle point) change with streamwise row number in the first three rows. However, there is no noticeable change after the third row except at the last row. Distinct flow characteristics can be observed at the endwall of the SDCF1 and SDCF2 arrays in Figs. 5(b) and (c). The general flow characteristics such as the horseshoe vortices at the upstream of a fin and the blockage effect from the downstream fins are similar to those of the UDCF array. However near wake flow especially in the initial rows shows quite different characteristics from those of the UDCF. This was expected due to the step-induced downward flow which altered the near-endwall flow at the sides and near wake of a fin. Chen (1996) investigated near-endwall flow around a steppeddiameter circular cylinder and found that the step induces large accelerations in the near-endwall flow and reduces near-endwall turbulence intensity in the near wake even altering the oscillatory behavior of the wake. For the SDCF1 array, no clear recirculation can be observed in the near wake of the first and second row fins. A striking observation is that the wake flow of the first row fins is drawn into the low pressure pockets just behind the second row fins despite the acceleration between the second row fins. This contrasts to the flow from the first row of the UDCF which appears to impinge directly on the cylinders in the second row. Another interesting observation is that the flow becomes similar to that with the UDCF as it goes to the downstream rows. It is not clear what makes these changes in flow character at this time. It may be that the turbulence, produced by the repeated blockage of fins, makes the flow stabilize to the characteristic pattern inherent in that array configuration. The SDCF2 array shows similar flow characteristics to those of the SDCF1 array.

\section{Average Mass Transfer Coefficients}

Figure 6 shows the variation of row-averaged Sherwood number with streamwise row number. In this figure, the row-averaged Sherwood number on the fin taken from Goldstein et al. (1994) is plotted together with the present row-averaged Sherwood number on the endwall. As expected, the Sherwood number in each row increases with Reynolds number. In general, the row-by-row Sherwood number variations of the UDCF, SDCF1 and SDCF2 arrays show that the Sherwood number varies in the initial three or four rows and maintains almost constant values after that. The Sherwood number variation in the initial rows depends on the fin shape and Reynolds number. For the UDCF array, while the Sherwood number increases continuously up to the fourth row before it reaches a constant value at $R e_{d, \mathrm{a}}=3000$ on the fin surface $\left(R e_{d, \mathrm{a}}=5000\right.$ on the endwall), the Sherwood number increases in the initial three rows and decreases slightly at the fourth row before it reaches almost constant value at $R e_{d, \mathrm{a}}=9000$ and 18,000. However, the Sherwood numbers for the SDCF1 and SDCF2 arrays increase continuously reaching near constant values at the fourth row regardless of the Reynolds number or fin shapes.

Chen (1996) investigated the effect of boundary condition on the mass transfer from single short cylinders in crossflow. He found that the boundary condition affects the local mass transfer distribution on the cylinder and its endwall in a small region where the virgorous corner vortex and 
step-induced vortices carry additional naphthalene vapors. However, the effect of boundary condition on the average mass transfer coefficients was negligible. Metzger and Haley (1982) studied heat transfer in the short pin-fin channel using conducting fins and non-conducting fins. They also found that both results are comparable within $\pm 10 \%$, which indicates that the effect of boundary condition on the pin-fin channel heat transfer is small. Assuming the effect of boundary condition is small, the separately measured mass transfer coefficients on the fins and endwalls are combined based on the area ratio. The variation of row-averaged Sherwood number on the fin-endwall combined surface with respect to the Reynolds number is presented in Figs. 7-9 for the UDCF, SDCF1, and SDCF2 arrays, respectively. The lines representing the first to the third row data are the least-square curve fit lines using the power law

$$
\overline{S h_{d, \mathrm{r} i}}=a R e_{d, \mathrm{~m}}^{b}
$$

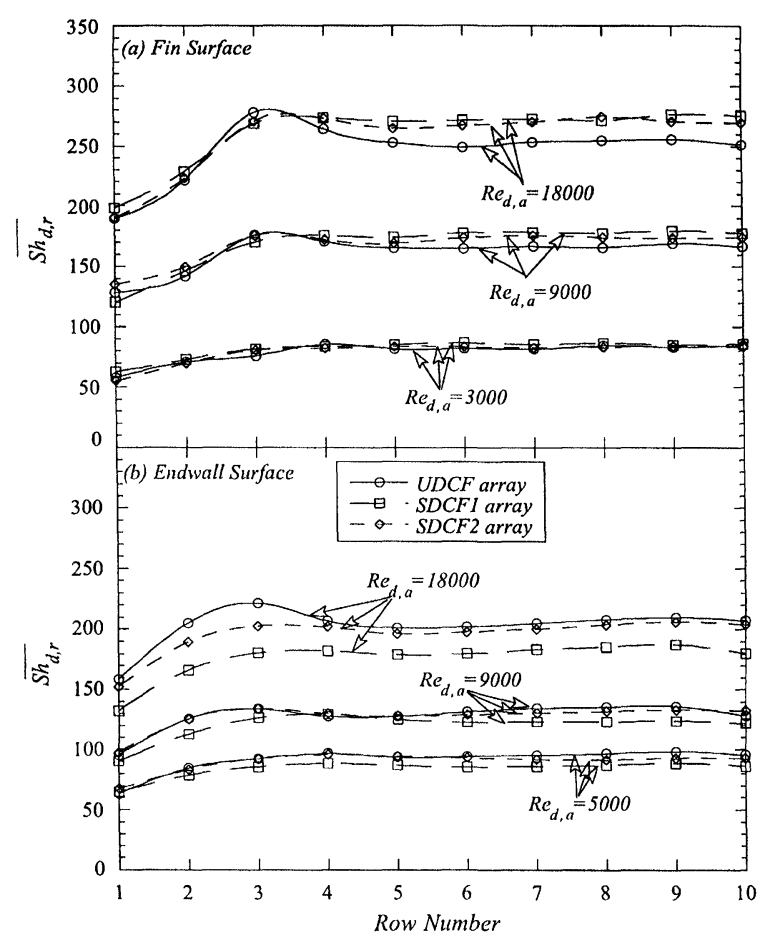

FIGURE 6 Row-averaged Sherwood number on the fin and endwall of the arrays: (a) fin surface and (b) endwall.

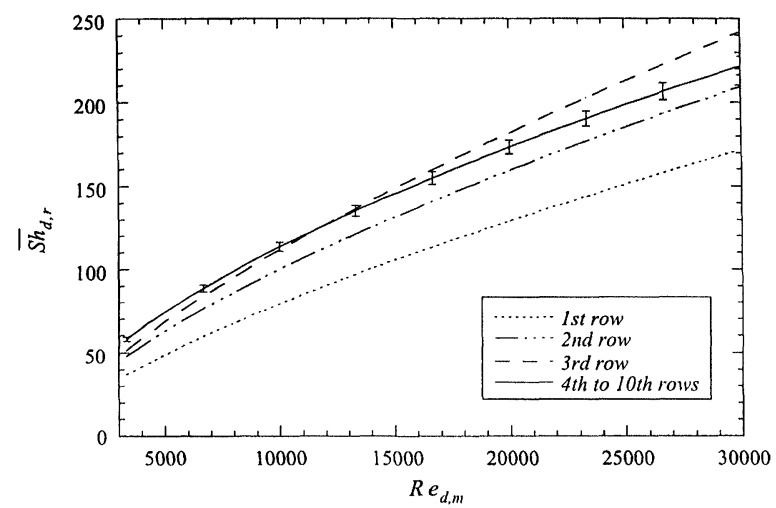

FIGURE 7 Row-averaged Sherwood number variation of the UDCF array (fin-endwall combined surface).

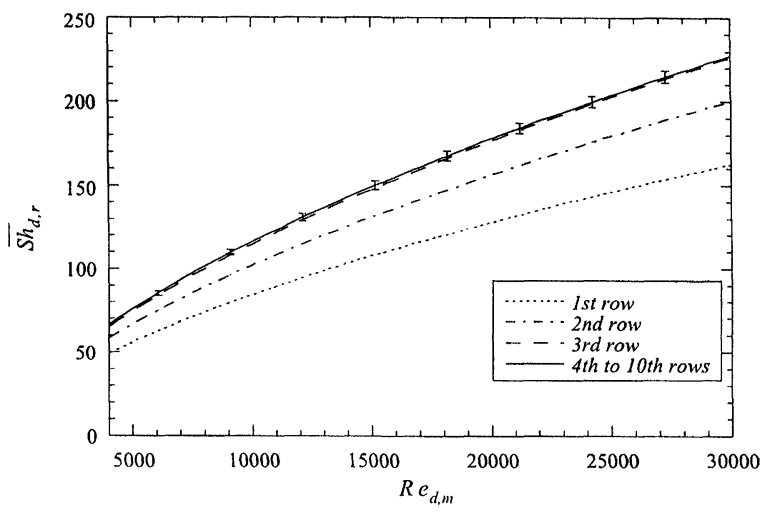

FIGURE 8 Row-averaged Sherwood number variation of the SDCF1 array (fin-endwall combined surface).

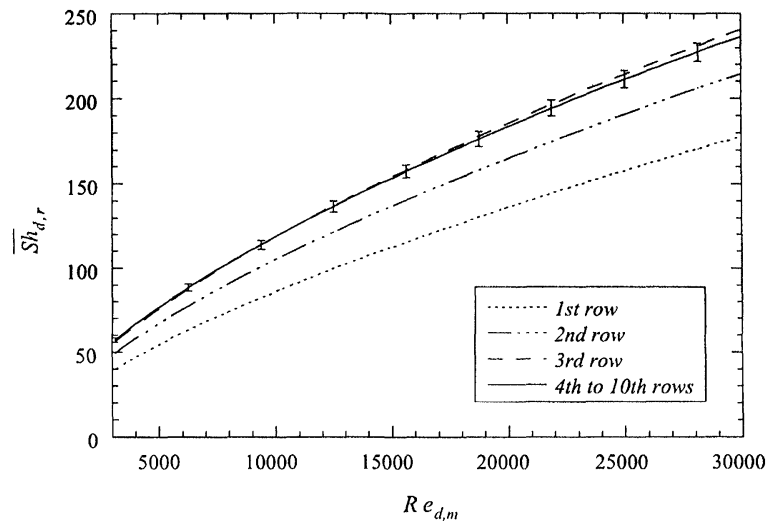

FIGURE 9 Row-averaged Sherwood number variation of the SDCF2 array (fin-endwall combined surface) 
and the lines representing the fourth row to the tenth row data are the least-square curve fit lines of the fully developed Sherwood number data using

$$
\overline{S h_{d, \mathrm{f}}}=a R e_{d, \mathrm{~m}}^{b},
$$

where $a$ and $b$ are the constant and exponent of correlation, respectively. While the Sherwood numbers at each row increase with the Reynolds number, their dependencies on Reynolds number change with streamwise row number and fin shapes. For all arrays, in general, the row-averaged Sherwood numbers in the initial three rows increase as the row number increases and their dependencies on Reynolds number change. However, from the fourth row to the tenth row, all the least-squares fitting lines of the row-averaged Sherwood numbers collapse into the fully developed Sherwood number correlations within the error bar range. The error bar presented in these figures represent $2.5 \%, 1.7 \%$, and $2.5 \%$ of the fully developed correlations for the UDCF, SDCF1, and SDCF2 arrays. The increases in row-averaged Sherwood number in the second, third, and fourth to the tenth rows relative to the first row are approximately $30 \%, 41 \%$, and $33 \%$, respectively for the UDCF array, $22 \%, 38 \%$, and $39 \%$, respectively for the SDCF1 array, and $21 \%$, $36 \%$, and $35 \%$, respectively for the SDCF2 array. The correlation constants and exponents of the row-averaged Sherwood number at the first, second, third rows and fully-developed Sherwood numbers are presented in Table I.
The array-averaged Sherwood numbers on the fin surface, endwall, and fin-endwall combined surface are presented in Fig. 10. On the fin surface, the array-averaged Sherwood numbers of the SDCF1 and SDCF2 arrays are higher than those of the UDCF array. Between the SDCF1 and SDCF2 arrays, the SDCF2 array shows slightly higher Sherwood number values than does the SDCF1 array. On the endwall, while the SDCF2 array shows higher array-averaged Sherwood number than the UDCF array, the SDCF1 array shows lower values than the UDCF array. As a result, the array-averaged Sherwood numbers on the combined surface reveal that the SDCF2 array has the highest Sherwood number and the UDCF array has the lowest Sherwood number at the same maximum velocity inside the pin-fin channel.

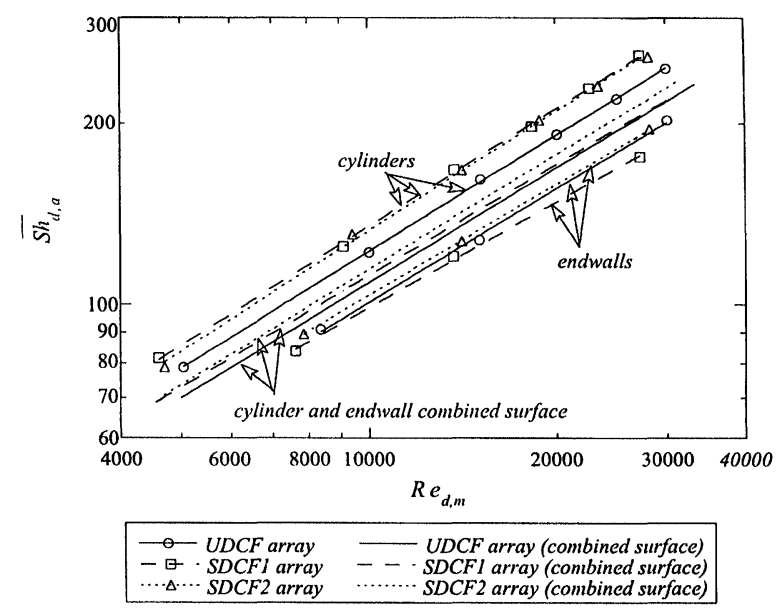

FIGURE 10 Array-averaged Sherwood number of the pinfin arrays: (fin, endwall, and combined surface).

TABLE I Correlation constants $a$ and exponents $b$ in Eqs. (14)-(16)

\begin{tabular}{|c|c|c|c|c|c|c|}
\hline \multirow[t]{2}{*}{ Row number } & \multicolumn{2}{|c|}{ UDCF array } & \multicolumn{2}{|c|}{ SDCF1 array } & \multicolumn{2}{|c|}{ SDCF2 array } \\
\hline & $a$ & $b$ & $a$ & $b$ & $a$ & $b$ \\
\hline First row & 0.121 & 0.704 & 0.344 & 0.598 & 0.195 & 0.661 \\
\hline Second row & 0.205 & 0.672 & 0.356 & 0.614 & 0.266 & 0.649 \\
\hline Third row & 0.169 & 0.705 & 0.377 & 0.621 & 0.315 & 0.644 \\
\hline FD* & 0.408 & 0.611 & 0.414 & 0.612 & 0.365 & 0.628 \\
\hline $\mathrm{AA}^{\dagger}$ & 0.319 & 0.633 & 0.393 & 0.613 & 0.335 & 0.633 \\
\hline
\end{tabular}

*FD: fully-developed Sherwood number.

${ }^{\dagger}$ AA: array-averaged Sherwood number. 
The array-averaged Sherwood numbers are nicely fitted using the power law,

$$
\overline{S h_{d, \mathrm{a}}}=a R e_{d, \mathrm{~m}}^{b}
$$

where the values of $a$ and $b$ of the combined surface are presented in Table I.

The separately measured mass transfer coefficients on the fins and the endwall provide a chance to explore the relative magnitude of mass transport from the fin and from the endwall. The ratios of mass transfer coefficients between the fins and endwall of the UDCF, SDCF1 and SDCF2 arrays are presented in Fig. 11. The figure indicates that while the ratio changes weakly with Reynolds number, it changes strongly with the fin shapes. On average, the array-averaged Sherwood numbers on the fins are higher than those of the endwalls by $23 \%, 41 \%$, and $31 \%$ for the UDCF, SDCF1, and SDCF2 arrays, respectively in the Reynolds number range investigated. There were large discrepancies among the published heat transfer results for this matter. VanFossen (1981) estimated that the heat transfer coefficient on a UDCF style fin is $35 \%$ higher than that on the endwall. Metzger and Haley (1982) and Chyu (1989) reported that the heat transfer coefficients on the fin and endwall are comparable within $\pm 10 \%$. Later, Metzger et al. (1984) re-evaluated this ratio using the same analytical model as VanFossen (1981) and reported that the fin surface

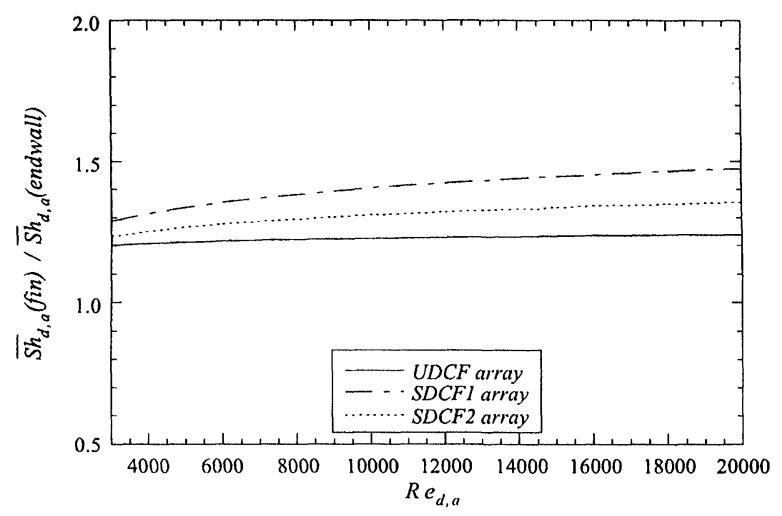

FIGURE 11 The ratio of array-averaged Sherwood numbers between the fins and endwall surfaces. has almost two times higher heat transfer coefficient than that of the endwall. Note that all of these results were obtained using the UDCF array with $H / d=1$. The present results are between those of VanFossen (1981) and Metzger and Haley (1982).

\section{Performance Analysis of the Pin-Fin Arrays}

For application of the short pin-fin array channel, the pressure loss penalty associated with the mass/ heat transfer enhancement is a key factor. Therefore, it will be important to evaluate the performance of the different arrays considering the heat transfer and pressure loss at the same time. Various methods have been developed for the overall performance evaluation of heat transfer systems. In the present study, the overall performances of the UDCF, SDCF1, and SDCF2 array are evaluated under two constraints: (a) the heat transfer rate for fixed pumping power and (b) the required heat transfer surface area and the resulting pressure loss to achieve the fixed heat load for fixed mass flow rate. For the analysis, present mass transfer coefficients are converted to the heat transfer coefficients using the analogy between heat and mass transfer, $\left(\overline{h_{i}} / \overline{h_{m, i}}\right)=(\mathrm{Pr} / \mathrm{Sc})^{n}$. The Prandtl number $\mathrm{Pr}=0.7$ and the Schmidt number $S c=2.28$ at $25^{\circ} \mathrm{C}$ are used together with the analogy $n$-factor of 0.4 . The pressure loss data taken from Goldstein et al. (1994) are also used for the analysis.

It is relatively straightforward to develop a general heat transfer relationship in a pin-fin channel. Note that the fully developed mass/heat transfer condition prevails after the third row of the pin-fin arrays and the pressure loss coefficient is defined on a per fin-row basis. Thus, it is possible to develop general relationships which can be applied for the arrays with many streamwise rows. Let $T_{\mathrm{b} i}$ be the bulk temperature of the fluid approaching the $i$ th row and $T_{\mathrm{w}}$ be the heat transfer surface temperature. Let the heat transfer surface temperature $\left(T_{\mathrm{w}}\right)$ and the flow temperature approaching the first row of an array $\left(T_{\mathrm{b} 1}\right)$ be the same for all arrays. Assuming the fluid is well mixed between successive rows, an energy balance for the $i$ th row 
gives

SDCF arrays and UDCF array becomes

$$
\overline{h_{i}} A_{\mathrm{w}}\left(T_{\mathrm{w}}-T_{\mathrm{b}, i}\right)=\dot{m} c_{p}\left(T_{\mathrm{b}, i+1}-T_{\mathrm{b}, i}\right)
$$

where $\overline{h_{i}}$ is a row-averaged heat transfer coefficient in the $i$ th row and $\dot{m}$ is the mass flow rate of fluid through the duct. Rearranging this equation yields

$$
\frac{T_{\mathrm{b}, i+1}-T_{\mathrm{w}}}{T_{\mathrm{b}, i}-T_{\mathrm{w}}}=1-\frac{\bar{h}_{i} A_{\mathrm{w}}}{\dot{m} c_{p}} .
$$

Applying $i=1,2,3, \ldots, N$ consecutively, and multiplying the resulting $N$ equations yields

$$
\begin{aligned}
& \frac{T_{\mathrm{b}, N+1}-T_{\mathrm{w}}}{T_{\mathrm{b}, 1}-T_{\mathrm{w}}} \\
& \quad=\left(1-\frac{\overline{h_{1}} A_{\mathrm{w}}}{\dot{m} c_{p}}\right)\left(1-\frac{\overline{h_{2}} A_{\mathrm{w}}}{\dot{m} c_{p}}\right) \cdots\left(1-\frac{\overline{h_{N}} A_{\mathrm{w}}}{\dot{m} c_{p}}\right) .
\end{aligned}
$$

The present results show that the mass/heat transfer coefficient varies in the first three rows and then reaches its fully developed value from the fourth row on. Let the fully developed heat transfer coefficient be $\overline{h_{\mathrm{f}}}$ and let

$$
\begin{aligned}
& K=\left(1-\frac{\overline{h_{1}} A_{\mathrm{w}}}{\dot{m} c_{p}}\right)\left(1-\frac{\overline{h_{2}} A_{\mathrm{w}}}{\dot{m} c_{p}}\right)\left(1-\frac{\overline{h_{3}} A_{\mathrm{w}}}{\dot{m} c_{p}}\right) \\
& \text { and } G=\left(1-\frac{\overline{h_{\mathrm{f}}} A_{\mathrm{w}}}{\dot{m} c_{p}}\right) .
\end{aligned}
$$

Then Eq. (18) can be rewritten as

$$
T_{\mathrm{b}, N+1}-T_{\mathrm{b}, 1}=\left(T_{\mathrm{w}}-T_{\mathrm{b}, 1}\right)\left(1-K G^{N-3}\right) .
$$

The heat transfer to the fluid from $N$ rows of pin-fins is

$$
\begin{aligned}
\dot{Q} & =\dot{m} c_{p}\left(T_{\mathrm{b}, N+1}-T_{\mathrm{b}, 1}\right) \\
& =\dot{m} c_{p}\left(T_{\mathrm{w}}-T_{\mathrm{b}, 1}\right)\left(1-K G^{N-3}\right) .
\end{aligned}
$$

Substituting $\dot{m}=\mu\left(A_{\min } / d\right) R e_{d, \mathrm{~m}}$ into Eq. (21) and noting that $\mu c_{p}\left(T_{\mathrm{w}} / T_{\mathrm{b}, 1}\right) / d$ values are same for all arrays, the ratio of heat transfer rates between the

$$
\frac{\dot{Q}_{\mathrm{SDCF}}}{\dot{Q}_{\mathrm{UDCF}}}=\frac{\left[A_{\min } R e_{d, \mathrm{~m}}\left(1-K G^{N-3}\right)\right]_{\mathrm{SDCF}}}{\left[A_{\min } R e_{d, \mathrm{~m}}\left(1-K G^{N-3}\right)\right]_{\mathrm{UDCF}}} .
$$

\section{Heat Transfer Rate at a Fixed Pumping Power}

The pumping power, $\dot{F}$, required to transport fluid with a mass flow rate $\dot{m}$ through the pressure loss $\Delta p_{\text {test }}$ is

$$
\dot{F}=\frac{\dot{m}}{\rho} \Delta p_{\text {test }}=\dot{F}=\left(\frac{\mu^{3} N}{2 \rho^{2} d^{3}}\right) \cdot f A_{\min } R e_{d, \mathrm{~m}}^{3}
$$

Since $\left(\mu^{3} N / 2 \rho^{2} d^{3}\right)$ values are the same for all arrays, the fixed pumping power condition leads to

$$
\begin{aligned}
{\left[f A_{\mathrm{min}} R e_{d, \mathrm{~m}}^{3}\right]_{\mathrm{UDCF}} } & =\left[f A_{\mathrm{min}} R e_{d, \mathrm{~m}}^{3}\right]_{\mathrm{SDCF} 1} \\
& =\left[f A_{\min } R e_{d, \mathrm{~m}}^{3}\right]_{\mathrm{SDCF} 2}
\end{aligned}
$$

If the pumping power requirement is non-dimensionalized using the Reynolds number of the UDCF array such that

$$
\Psi=\left[\operatorname{Re}_{d, \mathrm{~m}}\right]_{\mathrm{UDCF}}=\left[\frac{\dot{F}}{f A_{\min }}\left(\frac{2 \rho^{2} d^{3}}{\mu^{3} N}\right)\right]^{1 / 3},
$$

then the Reynolds numbers of the SDCF arrays corresponding to the power requirement are

$$
\left[R e_{d, \mathrm{~m}}\right]_{\mathrm{SDCF}}=\Psi\left[\frac{\left(f A_{\mathrm{min}}\right)_{\mathrm{UDCF}}}{\left(f A_{\min }\right)_{\mathrm{SDCF}}}\right]^{1 / 3}
$$

The Reynolds numbers of the SDCF1 and SDCF2 arrays which satisfy the fixed pumping power prescribed using the Reynolds number of the UDCF array can be evaluated from Eq. (26). The ratio of heat transfer rate of the pin-fin arrays can be calculated from Eq. (22) using the evaluated Reynolds number.

The results of this analysis are presented in Fig. 12. In this figure, the heat transfer enhancements of the SDCF1 and SDCF2 arrays relative to the UDCF array are plotted as a function of 


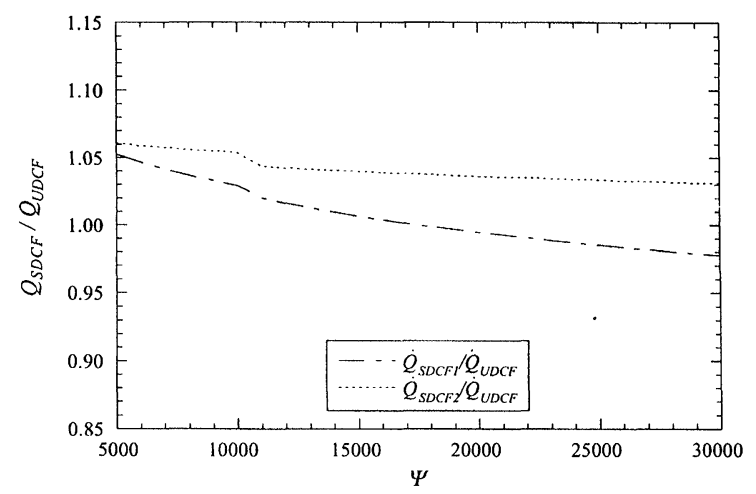

FIGURE 12 Heat/mass transfer rates of the SDCF1 and SDCF2 arrays relative to the UDCF array at a given $\Psi$.

non-dimensionalized pumping power, $\Psi$. The heat transfer enhancement rate shows decreasing trend with increasing $\Psi$. The SDCF2 array shows better overall performance than the UDCF array in the present pumping power range. The SDCF2 array has a $6 \%$ higher heat transfer rate at $\Psi=5000$ and $3 \%$ higher heat transfer rate at $\Psi=30,000$ than the UDCF array. On average, the SDCF2 array shows $4 \%$ higher heat transfer rate than the UDCF array at the same pumping power. The SDCF1 array provides about $5 \%$ higher heat transfer rate at $\Psi=5000$, but $2 \%$ lower heat transfer rate at $\Psi=30,000$ than the UDCF array. On average, the heat transfer rate of the SDCF1 array is almost the same as that of the UDCF array in the present pumping power range.

\section{Required Heat Transfer Area and Pressure Loss to Achieve Fixed Heat Load under the Same Mass Flow Rate}

The maximum possible heat transfer rate of the heat transfer system, $\dot{Q}_{\max }$, is determined by the maximum temperature difference in the system

$$
\dot{Q}_{\max }=\dot{m} c_{p}\left(T_{\mathrm{w}}-T_{\mathrm{b}, 1}\right)
$$

The effectiveness of the heat transfer system, which is defined as the ratio between actual heat transfer rate presented in Eq. (21) and maximum possible heat transfer rate of the system, is widely used as a parameter indicating the performance of a heat transfer system,

$$
\varepsilon=\frac{\dot{Q}}{\dot{Q}_{\max }}=1-K G^{N-3} .
$$

Note that all of the arrays have the same maximum possible heat transfer rate under the same mass flow rate and constant $T_{\mathrm{w}}$ and $T_{\mathrm{b} 1}$ condition. Therefore, the fixed heat duty condition corresponds to the fixed effectiveness condition. Using this concept, the required number of streamwise rows to achieve fixed heat load under the same mass flow rate condition can be evaluated from Eq. (28) as

$$
N=3+\frac{\ln [(1-\varepsilon) / K]}{\ln G}
$$

and the resulting pressure loss of the $N$-row array can be expressed in a non-dimensionalized form as

$$
f N\left(\frac{A_{\text {duct }}}{A_{\text {min }}}\right)=\frac{\Delta p_{\text {test }}}{(1 / 2) \rho u_{\text {ave }}^{2}} .
$$

The results of this calculation for the effectiveness values $\varepsilon=0.3,0.4$ and 0.5 are presented in Figs. 13(a), (b), and (c), respectively. In these figures, the ordinate has dual levels. One is the number of rows, $N$, which represents the required size of the heat transfer system. The other is the non-dimensionalized pressure loss, $f N\left(A_{\text {duct }} / A_{\text {min }}\right)$, which represents the resulting pressure loss of the system. While the SDCF1 array requires the largest heat transfer area, the SDCF2 array requires the smallest heat transfer area to fulfill fixed heat duty for all cases studied. The UDCF array shows higher pressure loss than SDCF arrays for all cases studied. Between the SDCF arrays, the SDCF1 array shows lower pressure loss than the SDCF2 array when the Reynolds number is less than 13,000. However, at the higher Reynolds number, the SDCF2 array shows slightly lower pressure loss than the SDCF1 array. Overall, the SDCF2 array shows the best performance. It requires less heat transfer area to achieve fixed heat load and produces less pressure 


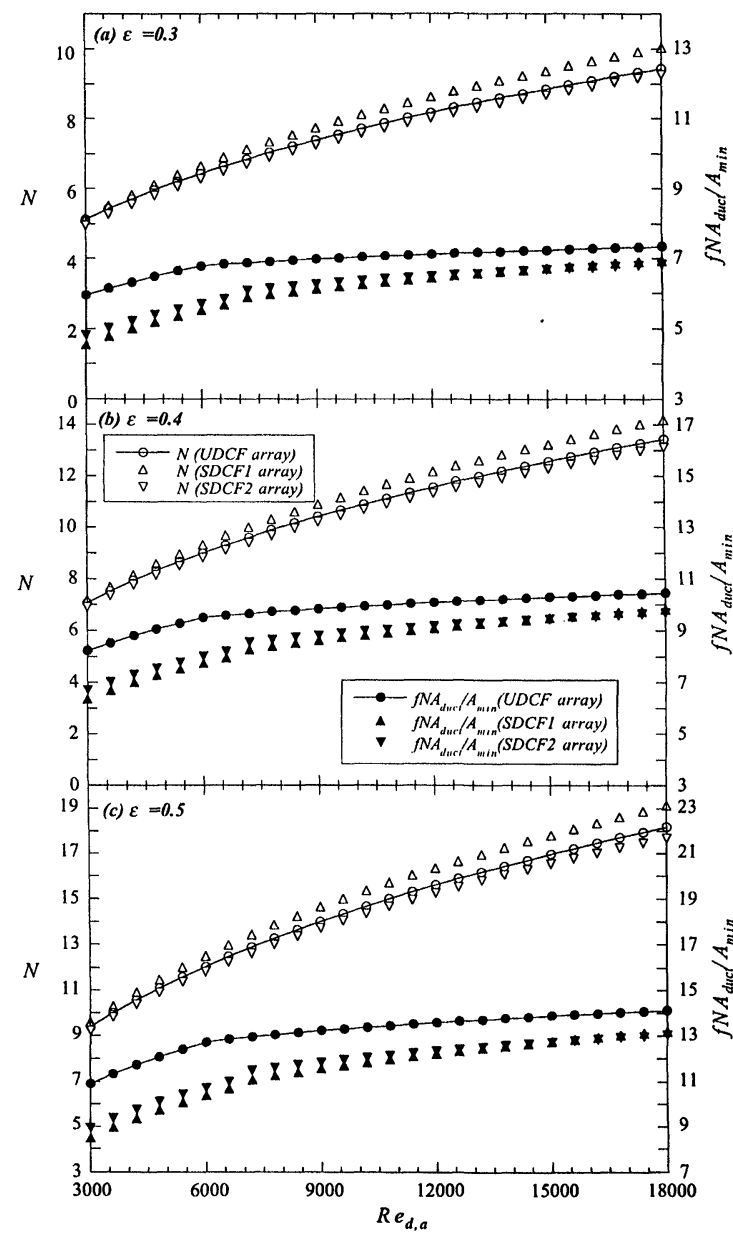

FIGURE 13 Required number of fin rows and pressure loss to fulfill fixed heat load at the same flow rate: (a) $\varepsilon=0.3$, (b) $\varepsilon=0.4$, and (c) $\varepsilon=0.5$.

loss than the UDCF array for the same mass flow rate. This implies that it is possible to make the heat transfer system more compact by utilizing the SDCF2 array than the UDCF array and also reducing the pressure loss or pumping power.

\section{SUMMARY AND CONCLUSION}

The near endwall flow and shear visualized using an oil-lampblack mixture painted on the surface reveals distinct flow characteristics associated with the pin-fin arrays. For every fin in the array, horseshoe vortices are generated upstream by the roll-up of endwall boundary layer, and a wake is present downstream of the fin from the flow separation on both sides of the fins. With a staggered arrangement of fins, these horseshoe vortices and wakes interact with each other producing a complex three-dimensional flow. For all arrays tested, the near-endwall flow varies row by row at the initial rows until it reaches a stable pattern after the third row. The row-averaged Sherwood number obtained from the naphthalene sublimation experiment also shows similar row-by-row variation characteristics. The relative magnitude of the array-averaged Sherwood number on the fin and the endwall were evaluated. The fin surface has higher array-averaged Sherwood number than the endwall and the ratio between them changes with fin shape and Reynolds number. Between arrays with different fin shapes, the SDCF2 array produces highest mass transfer rate and the SDCF1 array produces smallest pressure loss for the same approach flow.

The performance of the pin-fin arrays was analyzed under two different constraints. The SDCF2 arrays showed the best performance among the tested arrays. It produced the highest heat transfer enhancement at the same pumping power condition. It also required the smallest heat transfer area and produced the smallest pressure loss to achieve assigned heat load at the same mass flow rate condition. Even though the SDCF2 array showed better performance than the UDCF array, the heat transfer enhancement level achieved using it was smaller than expected. Higher endwall mass/heat transfer coefficients were expected using the SDCF arrays due to the step-induced secondary flow directed toward the endwall. But this step-induced flow altered the near wake flow characteristics. It not only accelerated the near endwall flow, but it also apparently decreased the near endwall turbulence intensity possibly due to the acceleration induced re-larminarization. The suppression of turbulence energy contained in a separating shear layer caused by the step may be another reason. As a result, the wakes of the SDCF arrays were not so effective in enhancing endwall mass/heat transfer compared to the wake of a UDCF array. 


\section{NOMENCLATURE}

$a \quad$ : coefficients in Eqs. (14)-(16) and Table I

$b \quad$ : exponents in Eqs. (14)-(16) and Table I

$A_{\text {duct }} \quad$ : cross-sectional area of the rectangular duct $\left(=35.56 \mathrm{~cm}^{2}\right)$

$A_{\text {min }} \quad:$ minimum free flow area inside the pin-fin channel $(=21.34,22.74$ and $23.46 \mathrm{~cm}^{2}$ for UDCF, SDCF 1 and SDCF2 arrays, respectively)

$A_{\mathrm{f}, \mathrm{b}} \quad$ : fin base area

$A_{\mathrm{w}} \quad:$ heat/mass transfer area bounded in each row of the array

$\left(=A_{\mathrm{w}, \text { fin }}+A_{\mathrm{w}, \text { endwall }}\right)$

$c_{p} \quad:$ specific heat of fluid

d : fin diameter or fin major diameter $(=13.34 \mathrm{~mm})$

$d_{\mathrm{m}} \quad$ : diameter of the middle cylinder of SDCF1 and SDCF2 $(=9.33 \mathrm{~mm})$

$D_{\mathrm{h}} \quad:$ hydraulic diameter of unobstructed duct $(=44.45 \mathrm{~mm})$

$D_{\text {na }} \quad$ : binary diffusion coefficient of naphthalene in air, Eq. (7)

$\dot{F} \quad$ : pumping power, Eq. (23)

$f \quad$ : pressure loss coefficient per fin row basis, Eq. (30)

$H \quad$ : height of duct and length of fin $(=26.67 \mathrm{~mm})$

$H_{\mathrm{s}} \quad$ : length of the cylinders at both ends of SDCF1 and SDCF2, Fig. 2

$\overline{h_{\mathrm{f}}} \quad$ : fully-developed heat transfer coefficient on fin-endwall combined surface

$\overline{h_{i}} \quad$ : fin-endwall combined row-averaged heat transfer coefficient at the $i$ th row

$h_{m} \quad$ : local mass transfer coefficient, Eqs. (1) and (3)

$\overline{h_{m, i}} \quad$ : fin-endwall combined row-averaged mass transfer coefficient at the $i$ th row

$\dot{m} \quad$ : mass flow rate of air through the duct

$\ddot{m} \quad$ : local mass transfer rate, Eq. (2)

$\dot{M}_{0-x} \quad$ : surface integrated mass transfer rate between $x=0$ to $x$ and $-S_{z} \leq z \leq S_{z}$, Eq. (4)

$N \quad$ : number of streamwise rows in array
$\Delta p_{\text {test }} \quad:$ pressure drop across the test section

$\operatorname{Pr} \quad$ : Prandtl number, $P r=0.7$ at $25^{\circ} \mathrm{C}$

$\dot{Q} \quad$ : heat transfer rate from the pin-fin array

$\dot{Q}_{\max } \quad$ : maximum heat transfer rate from the pin-fin array

$R e_{d, \mathrm{a}} \quad:$ Reynolds number based on $u_{\mathrm{ave}}$ and fin diameter, Eq. (12)

$R e_{d, \mathrm{~m}} \quad:$ Reynolds number based on $u_{\max }$ and fin diameter, Eq. (12)

Sc $\quad$ : Schmidt number, $S c=0.7$ at $25^{\circ} \mathrm{C}$

$S h_{d} \quad$ : local Sherwood number, Eq. (6)

$\overline{S h_{d, \mathrm{a}}} \quad$ : array-averaged Sherwood number (fin, endwall, and combined surface), Eq. (11)

$\overline{S h_{d, \mathrm{f}}} \quad$ : fully-developed Sherwood number (fin, endwall, and combined surface), Eq. (10)

$\overline{S h_{d, \mathrm{r} i}} \quad$ : row-averaged Sherwood number in the $i$ th row (fin, endwall, and combined surface),

$S_{x}, S_{z} \quad$ : streamwise and cross-stream pitches of the pin-fin array $(=33.34 \mathrm{~mm})$

$T_{\mathrm{b} i} \quad$ : bulk temperature of fluid at the inlet of the $i$ th row

$T_{\mathrm{w}} \quad:$ wall temperature or naphthalene surface temperature

$u_{\text {ave }} \quad:$ mean velocity in unobstructed duct or mean approach-flow velocity

: maximum velocity inside the pin-fin channel, $\dot{m} / \rho A_{\max }$

: volume flow rate of air between $-S_{z} \leq z \leq S_{z}$

$W \quad$ : width of rectangular channel

$x \quad$ : streamwise coordinate $(x=0$ at the begin of the naphthalene surface)

$z \quad$ : cross-stream coordinate $(z=0$ at the center of the channel width)

SDCF1 : stepped-diameter circular fin with $d_{\mathrm{m}} / d=0.7$ and $H_{\mathrm{s}} / H=1 / 4$, Fig. 2

SDCF2 : stepped-diameter circular fin with $d_{\mathrm{m}} / d=0.7$ and $H_{\mathrm{s}} / H=1 / 3$, Fig. 2

UDCF : uniform-diameter circular fin, Fig. 2

Sy : local net change in thickness of naphthalene 


\begin{tabular}{|c|c|}
\hline$\delta \tau$ & : wind tunnel running time \\
\hline 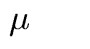 & : dynamic viscosity of air \\
\hline$\rho$ & : density of air \\
\hline$\rho_{\mathrm{n}, \mathrm{b} x}$ & $\begin{array}{l}\text { bulk concentration of naphthalene } \\
\text { vapor in approaching air at axial } \\
\text { station } x\end{array}$ \\
\hline$\rho_{\mathrm{n}, \mathrm{b} 0}$ & $\begin{array}{l}\text { bulk concentration of naphthalene } \\
\text { vapor in approaching air flow to } \\
\text { the test section }\end{array}$ \\
\hline$\rho_{\mathrm{n}, \mathrm{v}}$ & $\begin{array}{l}\text { naphthalene vapor concentration on } \\
\text { naphthalene surface }\end{array}$ \\
\hline ro & : density of solid naphthalene \\
\hline & $\begin{array}{l}\text { non-dimensional pumping power, } \\
\text { Eq. }(25)\end{array}$ \\
\hline & : effectiveness, Eq. (28) \\
\hline
\end{tabular}

\section{References}

Ambrose, D., Lawenson, I.J. and Sprake, C.H.S., 1975. The vapor pressure of naphthalene, J. Chem. Thermodyn., 7, 1173-1176.

Baker, C.J., 1980. The turbulent horseshoe vortex, J. Wind Eng. and Ind. Aerodyn., 6, 9-23.

Brigham, B.A. and VanFossen, G.J., 1984. Length to diameter ratio and row number effects in short pin fin heat transfer, ASME J. Eng. for Gas Turbine and Power, 106, 241-245.

Chen, S.B., 1996. Experimental Study of Flow and Local Mass/ Heat Transfer from Single Short Cylinders and Arrays of Short Cylinders in Crossflow, Ph.D. Thesis, University of Minnesota, Minneapolis, Minnesota.

Chen, S.B., Goldstein, R.J. and Jabbari, M.Y., 1994. Convective mass transfer and pressure loss characteristics of staggered short pin-fin arrays, Proc. 10th Int. Heat Transfer Conf., Vol. 3, pp. $7-12$.

Chyu, M.K., 1989. Heat Transfer and Pressure Drop for Short Pin-Fin Arrays with Fin-Endwall Fillet, ASME Paper No. 89-GT-99.

Eckert, E.R.G., 1976. Analogies to Heat Transfer Processes, Measurement in Heat Transfer (2nd ed.), pp. 397-423, edited by Eckert, E.R.G. and Goldstein, R.J., Hemisphere Publishing Corp., New York.

Goldstein, R.J. and Cho, H.H., 1995, A review of mass transfer measurement using naphthalene sublimation, Exp. Thermal and Fluid Science, 10, 416-434.

Goldstein, R.J. and Karni, J., 1984. The effect of a wall boundary layer on local mass transfer from a cylinder in crossflow, ASME J. Heat Transfer, 106, 260-267.

Goldstein, R.J., Chyu, M.K. and Hain, R.C., 1985. Measurement of local mass transfer on a surface in the region of the base of a protruding cylinder with a computer controlled data acquisition system, Int. J. Heat Mass Transfer, 28(5), $977-$ 985.

Goldstein, R.J., Jabbari, M.Y. and Chen, S.B., 1994. Convective mass transfer and pressure loss characteristics of staggered short pin-fin arrays, Int. J. Heat Mass Transfer, 37 (Suppl. 1), $149-160$.

Ireland, P.T. and Jones, T.V., 1986. Detailed Measurement of heat transfer on and around a pedestal in fully developed passage flow, Proc. 8th Int. Heat Transfer Conf., Vol. 3, pp. 975-980.

Kawamura, T., Hiwada, M., Mabuchi, I. and Kumada, M. 1984. Augmentation of turbulent heat transfer on a flat plate with a three-dimensional protuberance (First Report), Bulletin JSME, 27, 2787-2794

Kawamura, T., Hiwada, M., Mabuchi, I. and Kumada, M. 1985. Augmentation of turbulent heat transfer on a flat plate with a protuberance (Second Report), Bulletin JSME, 28 283-291.

Kline, S.J. and Mcklintock, F.A., 1953. Describing uncertainties in single sample experiments, Mech. Eng., 75, 3-8.

Lau, S.C., Han, J.C. and Batten, T., 1989b. Heat transfer, pressure drop, and mass flow rate in pin fin channels with long and short trailing edge ejection holes, $A S M E J$. Turbomachinery, 111, 116-123.

Lau, S.C., Han, J.C. and Kim, Y.S., 1989a. Turbulent heat transfer and friction in pinFin channels with lateral flow ejection, ASME J. Heat Transfer, 111, 51-58.

Lau, S.C., Kim, Y.S. and Han, J.C., 1985. Effects of Fin Configuration and Entrance Length on Local Endwall Heat/Mass Transfer in a Pin Fin Channel, ASME paper No. 85-WA/HT-62.

Metzger, D.E., Berry, R.A. and Bronson, J.P., 1981. Developing Heat Transfer in Rectangular Ducts with Arrays of Short Pin-Fins, ASME Paper No. 81-WA/HT-6.

Metzger, D.E., Fan, C.S. and Haley, S.W., 1984. Effects of fin shape and array orientation on heat transfer and pressure loss in pin fin array, ASME J. Eng. for Gas Turbine and Power, 106, 252-257.

Metzger, D.E., Fan, Z.X. and Shepard, W.B., 1983. Pressure loss and heat transfer through multiple rows of short pin fins, Proc. 7th Int. Heat Transfer Conf., Vol. 3, pp. 137-142.

Metzger, D.E. and Haley, S.W., 1982. Heat Transfer Experiment and Flow Visualization for Arrays of Short Pin Fins, ASME Paper No. 82-GT-138.

Peng, Y., 1984. Heat transfer and friction loss characteristics of pin fin cooling configurations, ASMEJ. Eng. for Gas Turbine and Power, 106, 246-251.

Steuber, G.D. and Metzger, D.E., 1986. Heat transfer and pressure loss performance for families of partial length pin fin arrays in high aspect ratio rectangular ducts, Proc. 8th Int. Heat Transfer Conf., San Francisco, Vol. 6, pp. 2915-2920

Van Dresar, N. and Mayle, R.E., 1986. Convection at the base of a cylinder with a horseshoe vortex, Proc. 8th Int. Heat Transfer Conf., Vol. 3, pp. 1121-1126.

VanFossen, G.J., 1981. Heat transfer coefficients for staggered arrays of short fins, ASME J. Eng. for Power, 104, 268-274. 


\section{ait \\ ENERGY MATERIALS}

M A N E Y publishing

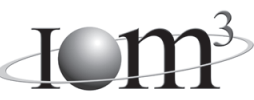

\section{Materials Science \& Engineering for Energy Systems}

Maney Publishing on behalf of the Institute of Materials, Minerals and Mining

The Institute of Materials, Minerals \& Mining

Economic and environmental factors are creating ever greater pressures for the efficient generation, transmission and use of energy. Materials developments are crucial to progress in all these areas: to innovation in design; to extending lifetime and maintenance intervals; and to successful operation in more demanding environments. Drawing together the broad community with interests in these areas, Energy Materials addresses materials needs in future energy generation, transmission, utilisation, conservation and storage. The journal covers thermal generation and gas turbines; renewable power (wind, wave, tidal, hydro, solar and geothermal); fuel cells (low and high temperature); materials issues relevant to biomass and biotechnology; nuclear power generation (fission and fusion); hydrogen generation and storage in the context of the 'hydrogen economy'; and the transmission and storage of the energy produced.

As well as publishing high-quality peer-reviewed research, Energy Materials promotes discussion of issues common to all sectors, through commissioned reviews and commentaries. The journal includes coverage of energy economics and policy, and broader social issues, since the political and legislative context influence research and investment decisions.

\section{CALL FOR PAPERS}

Contributions to the journal should be submitted online at http://ema.edmgr.com

To view the Notes for Contributors please visit: www.maney.co.uk/journals/notes/ema

Upon publication in 2006, this journal will be available via the Ingenta Connect journals service. To view free sample content online visit: www.ingentaconnect.com/content/maney

For further information please contact:

Maney Publishing UK

Tel: +44 (0)113 2497481 Fax: +44 (0)1132486983 Email: subscriptions@maney.co.uk

or

Maney Publishing North America

Tel (toll free): 8662975154 Fax: 6173546875 Email: maney@maneyusa.com

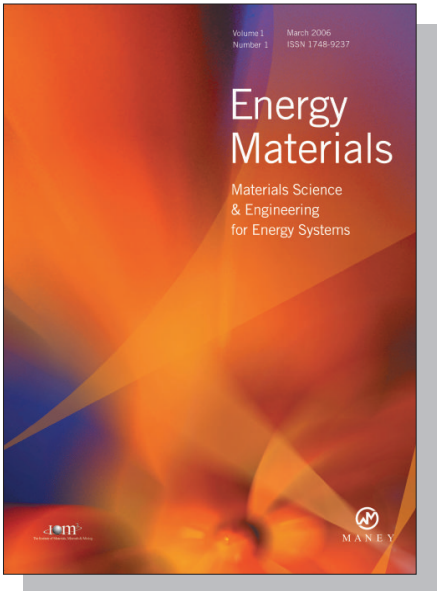

EDITORS

Dr Fujio Abe

NIMS, Japan

Dr John Hald, IPL-MPT, Technical University of Denmark, Denmark

Dr R Viswanathan, EPRI, USA

\section{SUBSCRIPTION INFORMATION}

Volume 1 (2006), 4 issues per year

Print ISSN: 1748-9237 Online ISSN: 1748-9245

Individual rate: $£ 76.00 / U S \$ 141.00$

Institutional rate: $£ 235.00 /$ US $\$ 435.00$

Online-only institutional rate: $£ 199.00 / U S \$ 367.00$

For special $\mathrm{IOM}^{3}$ member rates please email

subscriptions@maney.co.uk

\section{For further information or to subscribe online please visit www.maney.co.uk}



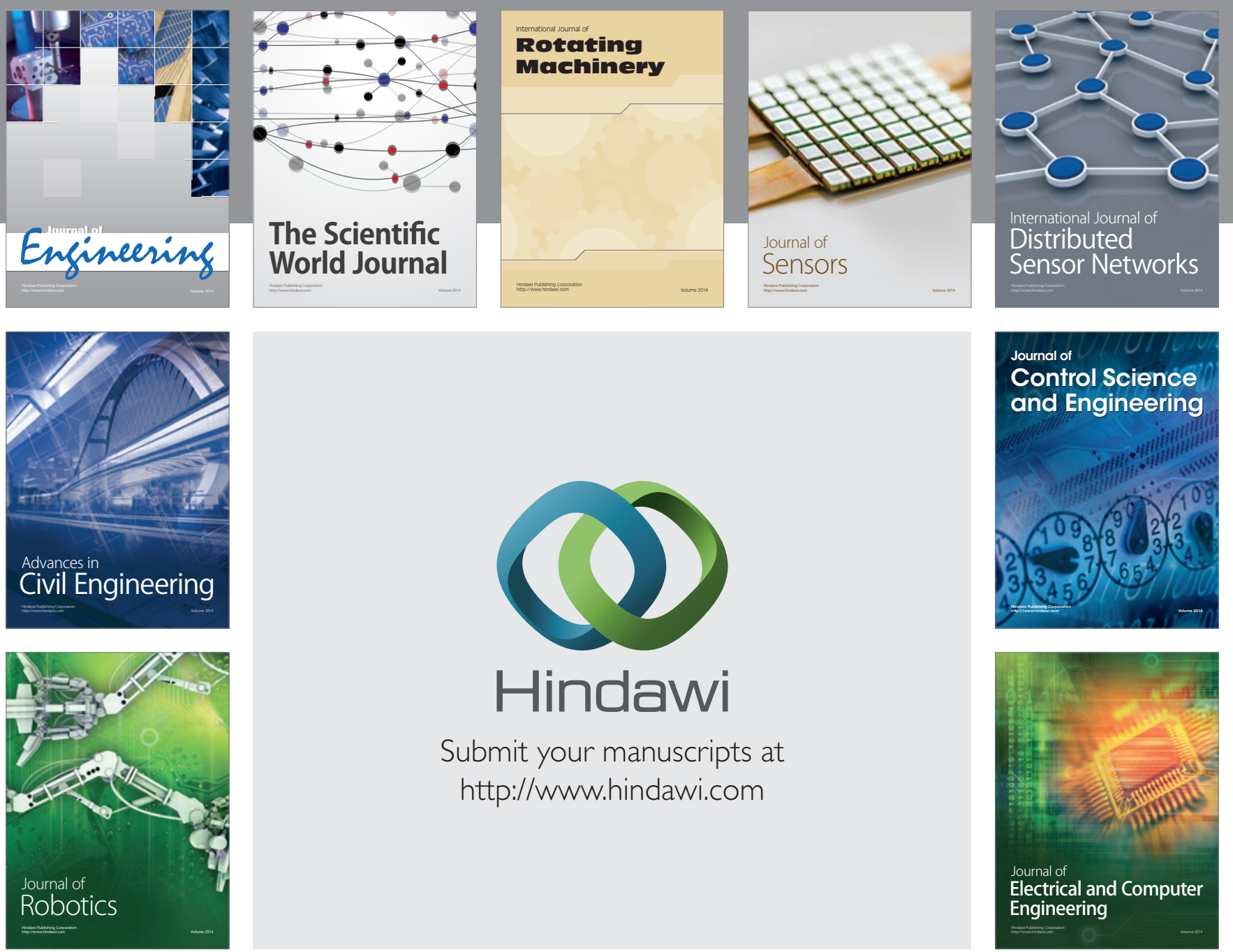

Submit your manuscripts at

http://www.hindawi.com
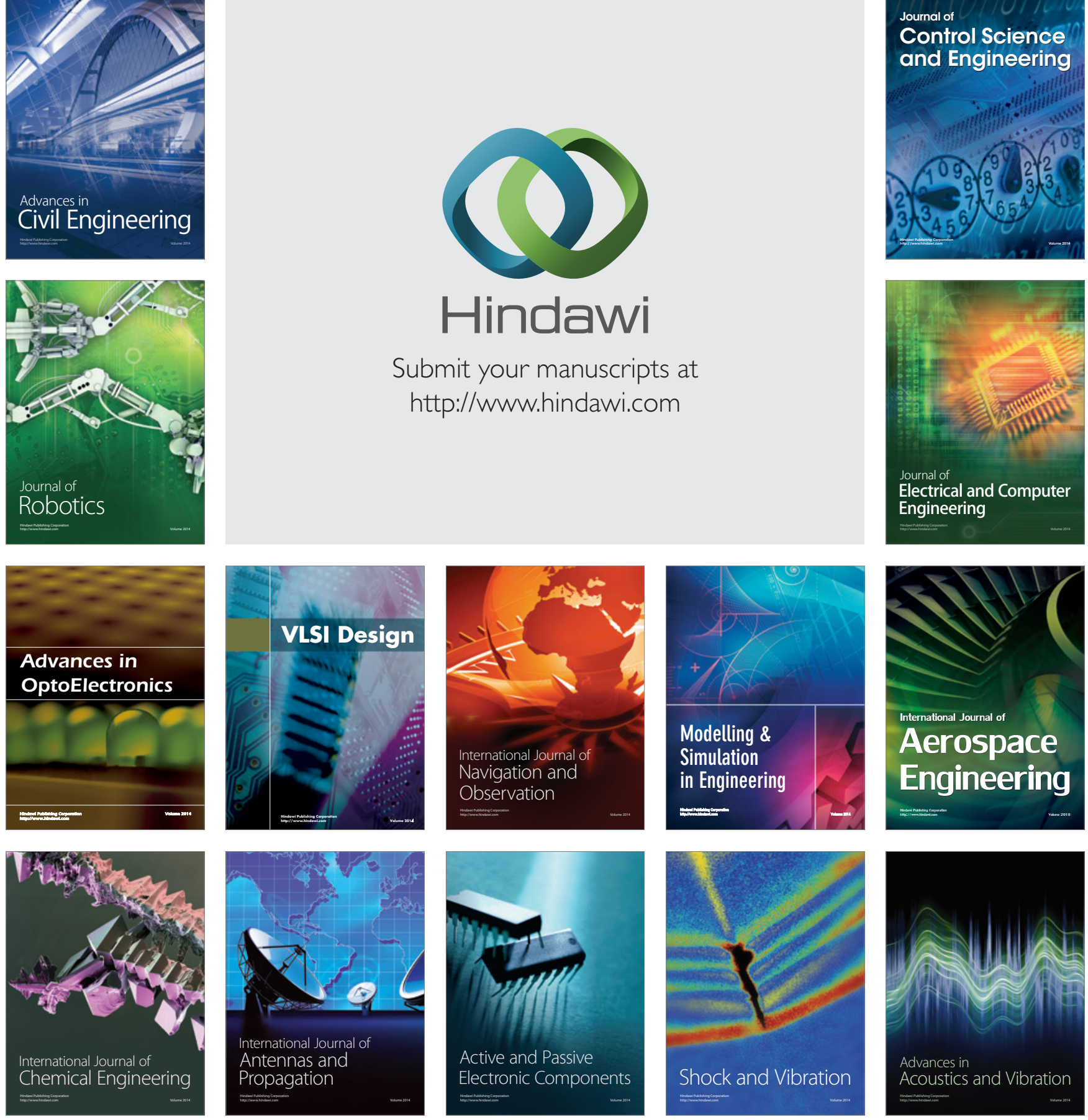